\title{
Employing artificial neural networks and fluorescence spectrum for food vegetable oils identification
}

\author{
Wawan Joko PRANOTO ${ }^{1}$, Sarmad Ghazi AL-SHAWI ${ }^{2}$, Paitoon CHETTHAMRONGCHAI ${ }^{3}$, Tzu-Chia CHEN ${ }^{4 *}$ (D), \\ Ekaterina PETUKHOVA ${ }^{5}$, Natalia NIKOLAEVA ${ }^{5}$, Walid Kamal ABDELBASSET ${ }^{6,7}$, \\ Natalya Anatolyevna YUSHCHENKO ${ }^{8}$, Surendar ARAVINDHAN ${ }^{9}$
}

\begin{abstract}
Vegetable oils (VOs) come in a wide range of flavors and trademarks. VOs are very similar in appearance, flavor, and taste, and it's frequently difficult to tell them from just by looking at them. Approaches for classifying these oils are sometimes expensive and time-intensive, and they frequently include analytical chemical techniques as well as mathematical algorithms like as Artificial Neural Networks (ANNs), Properties of Partial Least Squares (PLS), Principal Components Regression (PCR), and Principal Component Analysis (PCA) to enhance their effectiveness. Because of the large range of goods available, more productive techniques for qualifying, characterizing, and classifying these substances are required, as the ultimate cost should indicate the quality of the commodity that reaches the user. This study provides a technique for classifying VOs such as different manufacturers' soybean, corn, sunflower, and canola. This method utilized a Charge-Coupled Device (CCD) array sensor, a light emission diode, and a straightforward mathematical approach to capture the generated fluorescence spectrum (FS) in diluted oil. The spectrum classifications are performed using an ANN with three layers, each having four neurons. The approach can categorize $\mathrm{VO}$ and enables rapid network training with a $72 \%$ success rate utilizing only a few mathematical changes in the spectra data.
\end{abstract}

Keywords: vegetable oils quality; spectrometry; food; mathematical treatment.

Practical Application: Food vegetable oils identification using artificial neural networks and fluorescence spectrum.

\section{Introduction}

Because of advances in spectroscopy and the development of novel sensor technologies such as spectrophotometers and cameras, non-destructive and rapid assessments of quality-related factors in foods are becoming more common (Groß et al., 2019; Kucha et al., 2018). Researchers may now acquire data at the molecular level regarding physical and chemical components in food or biological materials because of advancements in spectroscopy (Abasi et al., 2018). Spectroscopic methods (e.g., ultra-violet spectroscopy, X-ray fluorescence spectroscopy (FS), mass spectroscopy, nuclear magnetic resonance spectroscopy, near-infrared spectroscopy, Fourier and Raman-transform infrared spectroscopy, atomic absorption spectroscopy) have been used to analyze infections caused by fungi in plant materials (e.g., seeds, fruits), to enhance the overall quality of food, safety, and sensory qualities, to explore structure-function connections in foods (both solid and liquid), and to study the movement of various chemical constituents in food ingredients (Boyaci et al., 2015; Esteki et al., 2018; Franca \& Nollet, 2017; McQueen et al., 1995; Nawrocka \& Lamorska, 2013; Petersen et al., 2021;
Pignataro et al., 2020; Shi et al., 2012; Szmatoła et al., 2018; Wang et al., 2017). It's typically complicated, problem-specific, and time-consuming to process, analyze, and show this data. Chemometrics is a well-established method for adjusting spectral data (Andre \& Soukoulis, 2020; Granato et al., 2018; $\mathrm{Xu}$ et al., 2020). Fluorescence signals are multi-dimensional data with overlapping fluorophore fingerprints (Ylldiz et al., 2017). Their processing is time-consuming and necessitates the use of sophisticated gear and software (Nishi et al., 2015; Ren et al., 2014). FS has been studied for a variety of applications, including the measurement of meat components, structural characteristics of cheese and meat, polyphenolic concentration in drinks, and yeast and bacterial cell differentiation, among others (Hassoun et al., 2019; Karoui \& Blecker, 2011; Sahar et al., 2016; Sikorska et al., 2005).

Chemometrics refers to all of the procedures that convert complicated data and analytical signals into usable knowledge. FS is usually analyzed in one of two ways: univariate or

\footnotetext{
Received 21 July, 2021

Accepted 23 Sept., 2021

${ }^{1}$ Department of Informatics, Faculty of Science and Technology, Universitas Muhammadiyah Kalimantan Timur, Samarinda, Indonesia

${ }^{2}$ Food Science Department, Agriculture College, Basrah University, Basrah, Iraq

${ }^{3}$ Faculty of Business Administration, Kasetsart University, Thailand

${ }^{4}$ Dhurakij Pundit University, Bangkok, Thailand

${ }^{5}$ K.G. Razumovsky Moscow State University of Technologies and Management - The First Cossack University, Moscow, Russian Federation

${ }^{6}$ Department of Health and Rehabilitation Sciences, College of Applied Medical Sciences, Prince Sattam bin Abdulaziz University, Al Kharj, Saudi Arabia

${ }^{7}$ Department of Physical Therapy, Kasr Al-Aini Hospital, Cairo University, Giza, Egypt

${ }^{8}$ Kazan Federal University, Kazan, Russia

${ }^{9}$ Department of Pharmacology, Saveetha Dental College and Hospital, Saveetha Institute of Medical and Technical Sciences, Chennai, India

*Corresponding author: tzuchiachen1688@gmail.com
} 
multivariate. The goal of the univariate analysis is to discover a couple of excitation-emission wavelengths in which the signal is produced by just one or a few known components (Ali et al., 2018; Christensen et al., 2005; Sádecká \& TóthoVá, 2007; Sikorska et al., 2019). Artificial Neural Network (ANN) and Channel Relationships techniques have been widely utilized to handle spectral data in recent years (Silva et al., 2015; Vasilescu et al., 2011). ANNs for simulation and modeling have gained popularity in various fields, including control, water treatment, chemical engineering, and energy (Molajou et al., 2021; Nourani et al., 2019a, b). The use of ANN in food chemistry and research is investigated (Gonzalez-Fernandez et al., 2019; Haroni et al., 2018; Zhou et al., 2019). ANN is a mathematical model of a certain structure made up of several single processing components (neurons, nodes) stacked in interconnected layers (Sharghi et al., 2018; Sharghi et al., 2019; Nourani et al., 2019c). Each input vector is multiplied using its weight, the products are added, and the sum is sent through a transfer function to generate the output (Bisgin et al., 2018). An ANN is made up of a collection of artificial neurons that are linked together. It has three layers: one for input, one for hiding, and one for output. Neurons can be found in each stratum. Each neuron receives information and changes it before sending it to other neurons with whom it is linked (Hernández, 2009; Pouladzadeh et al., 2016). The receiving neurons are used to calculate weights and biases. The network is tuned based on its capability to forecast a set of known outcomes using a subset or dataset of observations (Dash et al., 2020; Goñi et al., 2008).

Marine et al. (2007) used a mixture of two distinct neural network architectures to resolve simulated binary mixes of olive oils from various cultivars. Cámara et al. (2012) concluded that the Radial Basis Network (RBN) mathematical method proposed may be considered a reliable approach to monitor the stability of lycopene in tomato products (ketchups, sauces, and juices, etc.) during their shelf life and maybe a useful approach for monitoring lycopene degradation kinetics in tomato-based products using RBN with a mean prediction error lower than $2.62 \%$ and a correlation coefficient (CC) higher than 0.983 . Also, artificial neural networks were used to recognize patterns in the FS of olive oil (Gonzalez-Fernandez et al., 2019).

Food safety issues are major concerns in the food business that are linked to social and health advancement on a global scale (King et al., 2017; Olaimat et al., 2020). Consumers are increasingly searching for trustworthy food brands, and producers and merchants are expected to deliver high-quality goods (Fung et al., 2018). Food product authentication has become more complex as customer knowledge of food safety and quality problems has grown. However, the majority of these procedures are time intensive and need significant sample preparation, dangerous chemicals, and experienced and professional personnel (Ashurst \& Dennis, 2013; Danezis et al., 2016). Because of these drawbacks, new and easier techniques, such as fluorimetry, have been developed.

According to the vast number of trademarks for vegetable oils (VOs) on the Marketplace, it's usual to have doubts about whether the purchased material is truly pure. VOs have a lot of similarities in terms of color, smell, and flavor, and it's frequently impossible to tell them from just by looking at them. In this paper, based on a few mathematical manipulations and the use of ANN to distinguish the FS of VOs, we present a technique for their classification.

\section{Material and methods}

The data was collected using a spectrofluorometer type CCD/ LED created at the Federal University of Bahia (UFBA) in Brazil's Laboratory of Optical Properties (LAPO). FS between 350 and $1050 \mathrm{~nm}$ may be obtained using this apparatus. This apparatus was patented in 2012 and is listed in the QUIMIS catalog as Q-798FIL (Meira et al., 2014, 2015; Tomazzoni et al., 2014). Figure 1 indicates a schematic diagram of a spectrofluorometer. A Light Emitting Diode (LED) is utilized as the source of

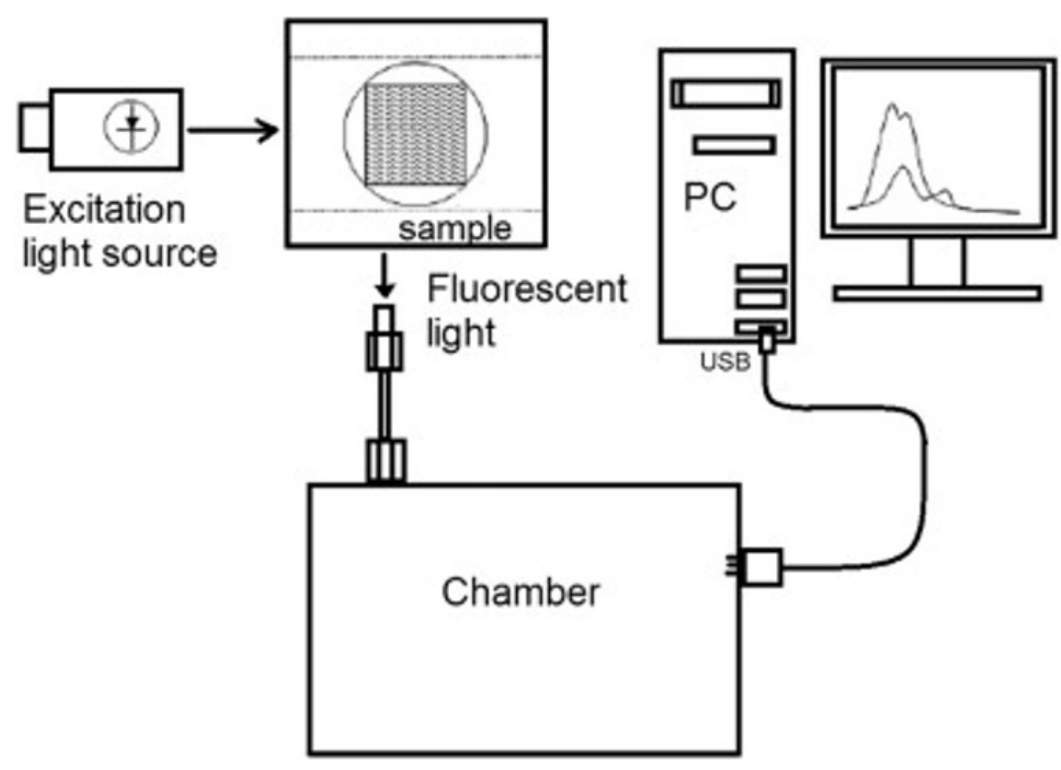

Figure 1. The LED/CCD spectrofluorimeter Q-798FIL. 
excitation light. Standard $3.5 \mathrm{~mL}$ cuvettes, microscope slides, or micro cuvettes may all be placed in the sample container. The LED emits short-wavelength light on the sample, which is then converted into fluorescent light of a different wavelength. The detector captures both fluorescence light from the sample and dispersed light from the LED optical system.

There are ten different VO brands available at local shops in Salvador. Several of them make several different types of VO (Soybean, Corn, Sunflower, and Canola). Using four distinct VOs, they may be categorized into six separate brands. Each oil was divided into twenty dilutions, yielding 480 samples in total. The neural network was trained using them. We created 158 additional samples from another batch, using two brands for each oil, to construct the validation set employing the same technique. Every sample was made by diluting the VO in heptane in a volume of $30 \mathrm{~mL}$ and varying the amount of the VO from $5 \%$ to $100 \%$ in $5 \%$ increments. Oils of the same labels used during training but from various production batches were utilized to validate the network and the categorization technique created.

\subsection{Data collection and analysis}

A $382 \mathrm{~nm}$ light-emitting diode was used as the excitation source for the FS. The CCD was maintained active for $1000 \mathrm{~ms}$ during the fluorescence light collecting. This time is referred to as integration time, and it is used to charge the metal-oxidesemiconductor (MOS) structure of each CCD pixel. The electrons from the CCD's active outer layer, where the photoelectric effect occurs, charge the CCD like an "almost capacitor." The data carried by the fluorescence photons is accumulated in the form of electrical charge as a result. The apparatus is cleared of its content at the conclusion of the integration time. An analog to digital converter receives the voltage gathered in each pixel and converts it to digital, resulting in wavelength data and light intensity in a two-dimensional array. To obtain spectral data, each sample was exposed to light for 15 seconds. It was necessary to conduct certain mathematical calculations:

1) The LED spectrum A was first subtracted from the overall spectrum to get the sample fluorescence known as FLU.

2) Following that, a constant $C$ was used to split the FLU.

The maximum fluorescence intensity observed for the sum of 640 samples was $C=10,422.95$ in this research ( $100 \%$ corn oil). This division facilitates comparisons by obtaining normalized spectra (NOR).

\subsection{Ann training}

The number of neurons in the hidden layer of the ANN was changed from 3 to 13 to get the best possible classification results. The number of successful examples in the hidden layer dwindled as the number of neurons increased. In the buried layer, there were four neurons with the most effective instances. The best efficiency was found between 1 and $4000 \mathrm{~nm}$ across a wide range of weights. The network mistakes were considerably different while utilizing shorter gaps for the weights. The feedforward supervised approach was utilized for training the ANN in this study, as shown in Figure 2. Each layer of the ANN has four neurons. The material to be categorized is described as follows in the output layer. Each neuron's output has a binary value of false (0) or true (1), and there are no combinations with more than one true neuron. As a result, the scenarios that may occur are as follows: for Soybean [ $\left[\begin{array}{llll}0 & 0 & 0 & 1\end{array}\right]$, for Corn [ $\left[\begin{array}{llll}0 & 0 & 1 & 0\end{array}\right]$, for

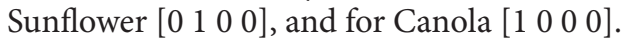

MATLAB $^{\circledast}$ was used to create the neural network. As previously stated, several alternative layouts and network parameters were explored, with the configuration with four neurons in each layer providing the best results.

\section{Results and discussion}

An empty bucket was put in the sample container in order to get the spectrum A mentioned before. To put it another way, it's a device that doesn't contain any samples. Figure 3 shows the spectrum of LED excitation. Light dispersed by the bucket walls reaches the detecting fiber. The spectrofluorimeter employed can measure fluorescence light between 350 and 1050 nanometres, as seen in this diagram. The existence of LED light $(382 \mathrm{~nm})$ was obviously reliant on the quantity of dispersed excitation light

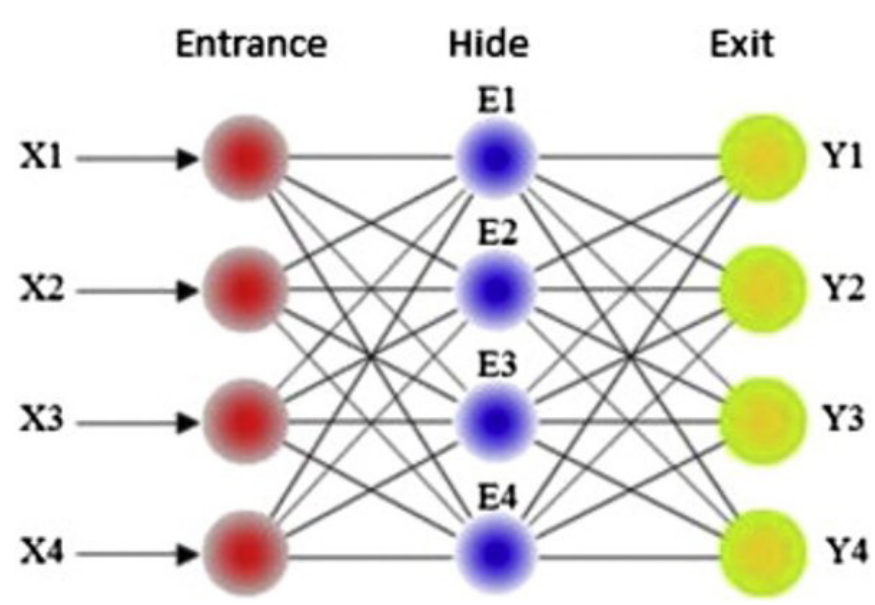

Figure 2. ANN model.

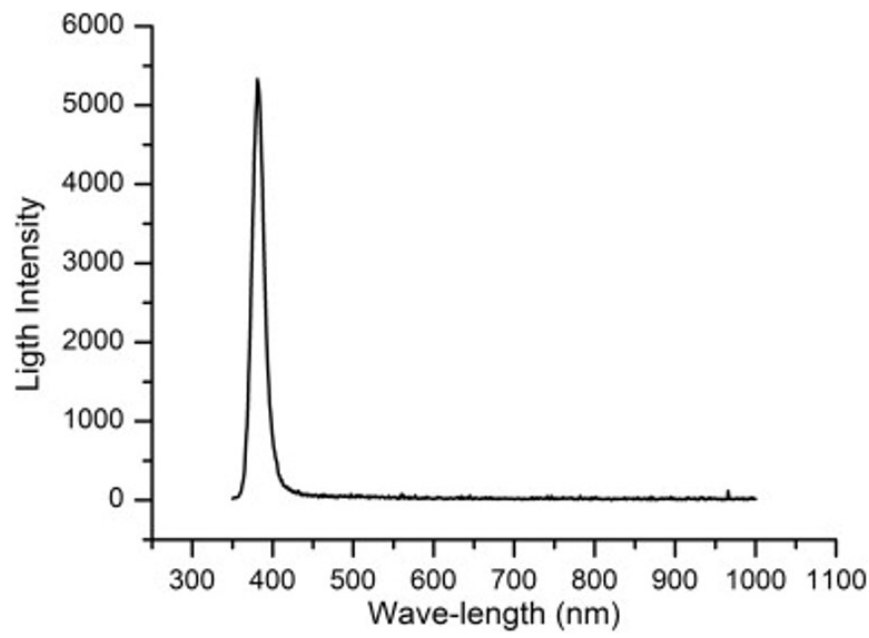

Figure 3. The empty fluorimeter/ LED spectrum's light spectrum. 
that did not interact with the fluorescent medium in certain samples, as shown by the measured spectra. The dispersed light from the LED was more prominent for tiny quantities of the oils at various dilutions. Spectra of canola oil (Bom Preço brand) samples at various dilutions ranging from 5 to $100 \%$ are shown in Figure 4.

Figure 5 shows the spectra of all VOs (soybean, corn, sunflower, and canola) utilized at a concentration of $100 \%$ for the excitation light (LED) centered at $382 \mathrm{~nm}$. Although the spectra were comparable, having peaks that were extremely near to one another, the intensity of light was very different. The numerical separation of even extremely close peaks was possible. As a result, the FS were highly distinctive and could be utilized to determine the oil type.
Nikolova et al. (2012) discovered similar spectra as well. When the network training time was compared to the training time for the previous approach in all spectra (Silva et al., 2015), the network training was determined to be 1.2 times quicker. As previously stated, The LED spectrum was removed from the total spectrum as the only mathematical treatment of the spectra and the result was divided by 10.42295 . The spectra for the various VOs utilized in ANN training are given in Figure 6, resulting from this mathematical method.

In the validation tests, the ANN's responses are shown in Table 1. The approach was successful in 2 situations, and the best effects may be seen in soybean (brand Liza) and corn (brand Mazola) oils. Only 5 of the Sunflower oil (brand Bom Preço) samples were accurately identified, which was the poorest

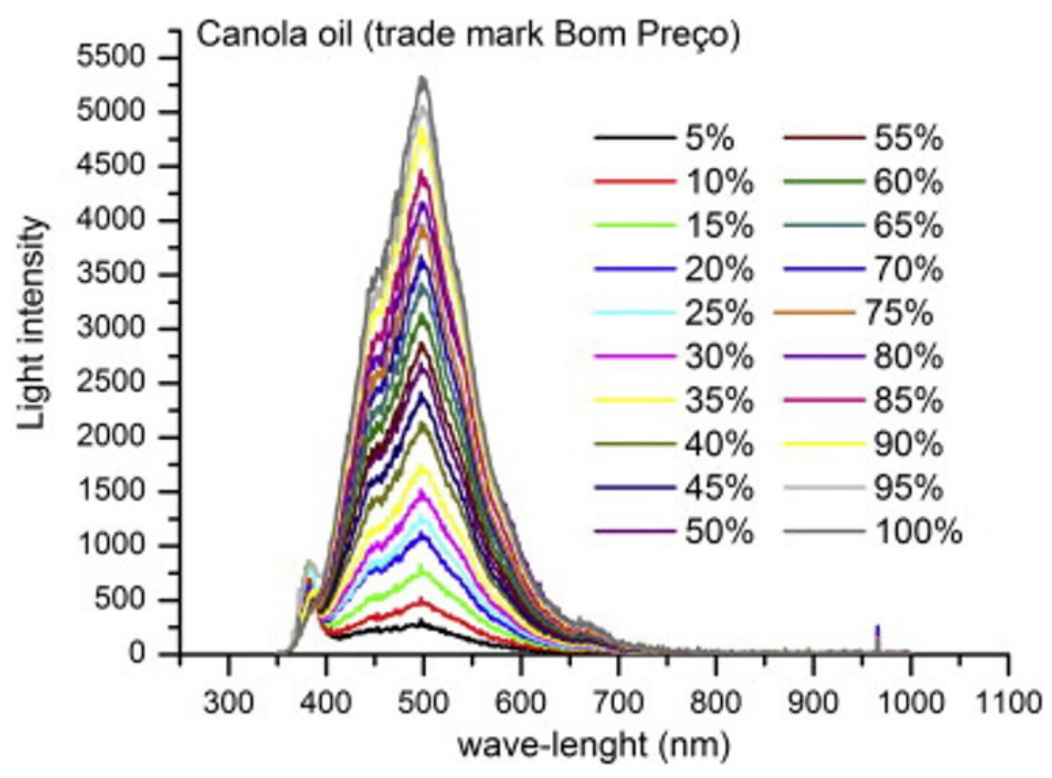

Figure 4. Canola oil light spectra at concentrations ranging from 5\% to $100 \%$.

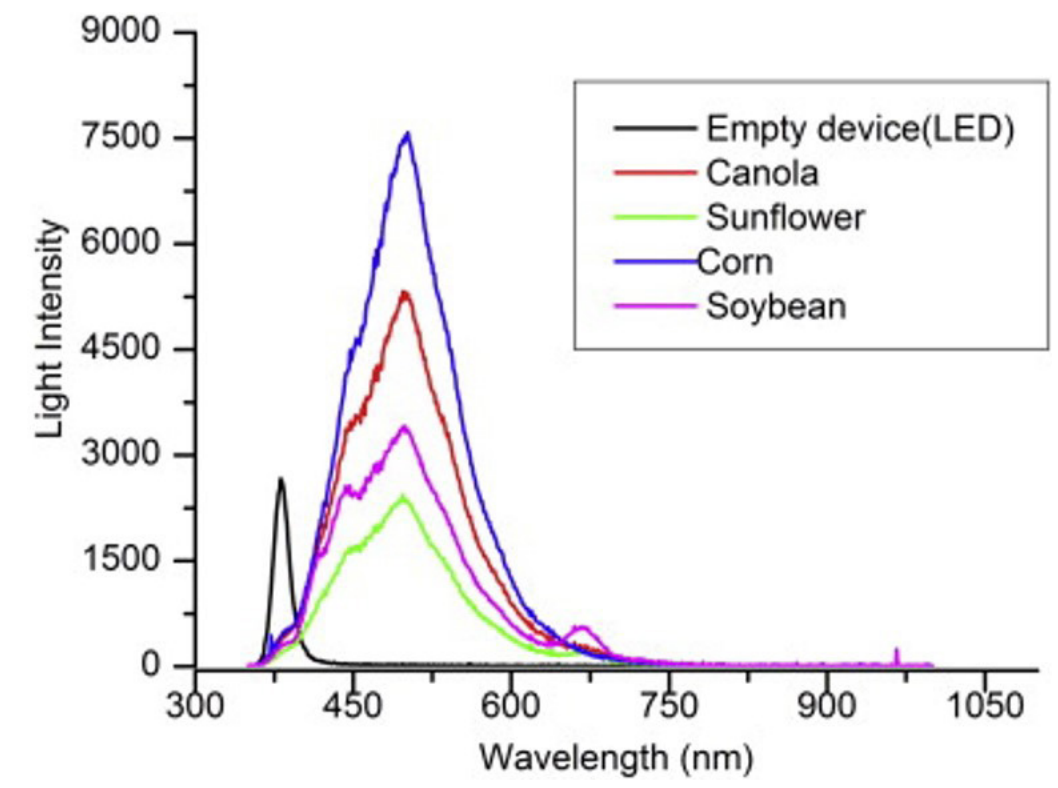

Figure 5. Four VOs' light spectra and an empty apparatus. 


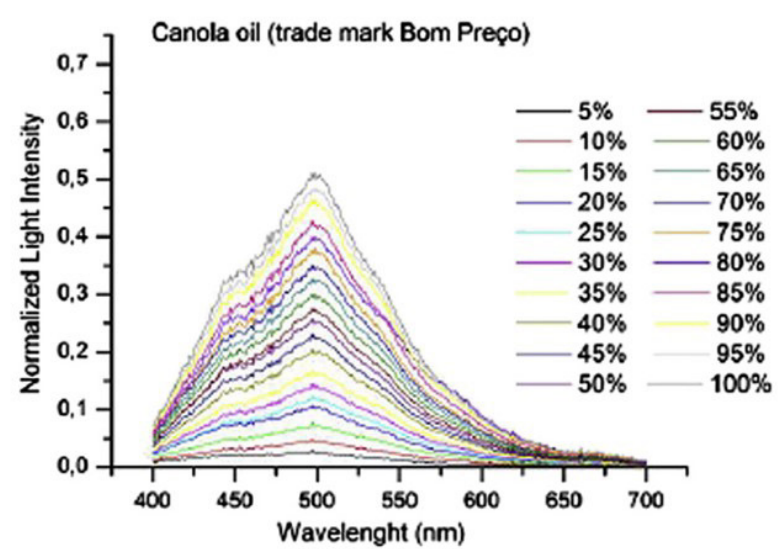

(a)

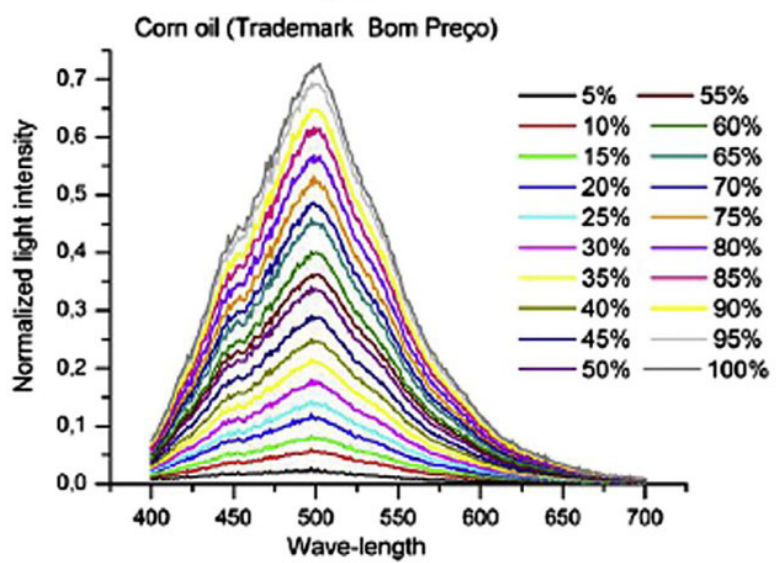

(c)

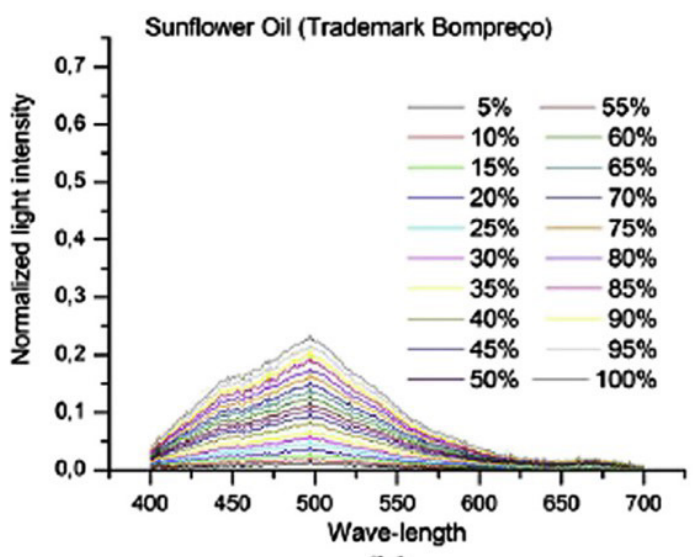

(b)

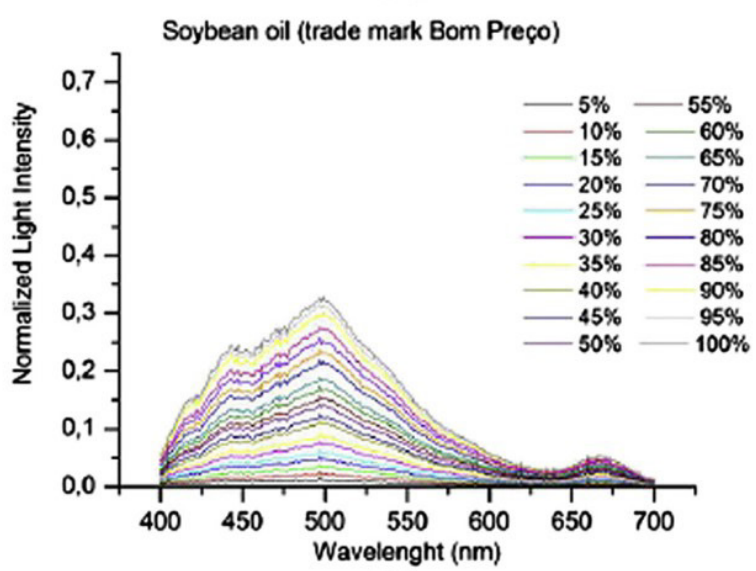

(d)

Figure 6. After the mathematical procedure, the spectra of soybean, corn, sunflower, and canola oils (Bom Preço brand) were obtained.

Table 1. The ANN's responses in 158 validation tests.

\begin{tabular}{ccc}
\hline Oil & Trademark & Total success in 20 samples \\
\hline Soybean & Soya & 18 \\
Corn & Salada & 18 \\
Canola & Qualitá & 10 \\
Corn & Mazola & 20 \\
Sunflower & Liza & 18 \\
Soybean & Liza & 20 \\
Canola & Bom Preço & 17 \\
Sunflower & Bom Preço & 5 \\
\hline
\end{tabular}

result of all. During earlier testing, it was discovered that some Sunflower samples' FS have been much more identical to those of canola oil samples, and the network was unable to differentiate between them.

A technical modification of fats and oils allows more flexibility in the selection of raw materials and helps to adjust the trends among local supply and demand in order to satisfy market demands and offer homogenous products from raw variables.

\section{Conclusions}

It was decided to create an approach based on artificial neural networks. This approach enables quick network training and only utilizes a few arithmetic operations on the spectra data. From the perspective of VO quality management, this is a promising technique that may be utilized to design future research focusing on the resolution of actual blends of oils from different cultivars, namely for soybean and corn oils. More research on canola and sunflower oils is needed to enhance categorization precision. The requirement for thorough research of the features that characterize the regions of interest across the FS is confirmed by this novel technique, which uses the most relevant characteristics of the FS as input data for ANN. Thus, interpreting the data from FS of VOs and other more sophisticated compounds requires first examining the fluorescence of the basic components that make up the samples to be examined.

\section{References}

Abasi, S., Minaei, S., Jamshidi, B., \& Fathi, D. (2018). Dedicated nondestructive devices for food quality measurement: a review. Trends in Food Science \& Technology, 78, 197-205. http://dx.doi.org/10.1016/j. tifs.2018.05.009.

Ali, H., Saleem, M., Anser, M. R., Khan, S., Ullah, R., \& Bilal, M. (2018). Validation of fluorescence spectroscopy to detect adulteration of edible oil in extra virgin olive oil (EVOO) by applying chemometrics. Applied Spectroscopy, 72(9), 1371-1379. http://dx.doi. org/10.1177/0003702818768485. PMid:29712442. 
Andre, C. M., \& Soukoulis, C. (2020). Food quality assessed by chemometrics. Foods, 9(7), 897. http://dx.doi.org/10.3390/foods9070897.

Ashurst, P. R., \& Dennis, M. J. (2013). Food authentication. New York: Springer.

Bisgin, H., Bera, T., Ding, H., Semey, H. G., Wu, L., Liu, Z., Barnes, A. E., Langley, D. A., Pava-Ripoll, M., Vyas, H. J., Tong, W., \& Xu, J. (2018). Comparing SVM and ANN based machine learning methods for species identification of food contaminating beetles. Scientific Reports, 8(1), 6532. http://dx.doi.org/10.1038/s41598-018-24926-7. PMid:29695741.

Boyaci, I. H., Temiz, H. T., Geniş, H. E., Soykut, E. A., Yazgan, N. N., Güven, B., Uysal, R. S., Bozkurt, A. G., İlaslan, K., Torun, O., \& Şeker, F. C. D. (2015). Dispersive and FT-Raman spectroscopic methods in food analysis. RSC Advances, 5(70), 56606-56624. http://dx.doi. org/10.1039/C4RA12463D.

Cámara, M., Fernández-Ruiz, V., Redondo, D. F., Sánchez-Mata, M. C., \& Torrecilla, J. S. (2012). Radial basis network analysis to estimate lycopene degradation kinetics in tomato-based products. Food Research International, 49(1), 453-458. http://dx.doi.org/10.1016/j. foodres.2012.07.030.

Christensen, J., Ladefoged, A. M., \& Nørgaard, L. (2005). Rapid determination of bitterness in beer using fluorescence spectroscopy and chemometrics. Journal of the Institute of Brewing, 111(1), 3-10. http://dx.doi.org/10.1002/j.2050-0416.2005.tb00642.x.

Danezis, G. P., Tsagkaris, A. S., Camin, F., Brusic, V., \& Georgiou, C. A. (2016). Food authentication: techniques, trends \& emerging approaches. Trends in Analytical Chemistry, 85, 123-132. http:// dx.doi.org/10.1016/j.trac.2016.02.026.

Dash, K. K., Raj, G., \& Gayary, M. A. (2020). Mathematical and Statistical Applications in Food Engineering. Application of neural networks in optimizing different food processes. Boca Raton: CRC Press.

Esteki, M., Shahsavari, Z., \& Simal-Gandara, J. (2018). Use of spectroscopic methods in combination with linear discriminant analysis for authentication of food products. Food Control, 91, 100-112. http:// dx.doi.org/10.1016/j.foodcont.2018.03.031.

Franca, A. S., \& Nollet, L. M. (2017). Spectroscopic methods in food analysis. Boca Raton: CRC Press. http://dx.doi.org/10.1201/9781315152769.

Fung, F., Wang, H.-S., \& Menon, S. (2018). Food safety in the 21st century. Biomedical Journal, 41(2), 88-95. http://dx.doi.org/10.1016/j. bj.2018.03.003. PMid:29866604.

Goñi, S. M., Oddone, S., Segura, J. A., Mascheroni, R. H., \& Salvadori, V. O. (2008). Prediction of foods freezing and thawing times: artificial neural networks and genetic algorithm approach. Journal of Food Engineering, 84(1), 164-178. http://dx.doi.org/10.1016/j. jfoodeng.2007.05.006.

Gonzalez-Fernandez, I., Iglesias-Otero, M. A., Esteki, M., Moldes, O. A., Mejuto, J. C., \& Simal-Gandara, J. (2019). A critical review on the use of artificial neural networks in olive oil production, characterization and authentication. Critical Reviews in Food Science and Nutrition, 59(12), 1913-1926. http://dx.doi.org/10.1080/10408398.2018.1433 628. PMid:29381389.

Granato, D., Putnik, P., Kovačević, D. B., Santos, J. S., Calado, V., Rocha, R. S., Cruz, A. G. D., Jarvis, B., Rodionova, O. Y., \& Pomerantsev, A. (2018). Trends in chemometrics: food authentication, microbiology, and effects of processing. Comprehensive Reviews in Food Science and Food Safety, 17(3), 663-677. http://dx.doi.org/10.1111/15414337.12341. PMid:33350122.

Groß, B., Hintschich, S., Tošic, M., Bourgos, P., Tsoumanis, K., \& Bertani, F. R. (2019). Phas-maFOOD-A miniaturized multi-sensor solution for rapid, non-destructive food quality assessment. In J. Beyerer, F.
Puente León, \& T. Längle (Eds.), OCM 2019-Optical Characterization of Materials: Conference Proceedings (pp. 99-109). Karlsruhe: KIT Scientific Publishing.

Haroni, S., Sheykhdavodi, M. J., \& Kiani, M. K. D. (2018). Application of artificial neural networks for predicting the yield and GHG emissions of sugarcane production. Mashin/Ha-Yi Kishavarzi, 8(2), 389-401.

Hassoun, A., Sahar, A., Lakhal, L., \& Aït-Kaddour, A. (2019). Fluorescence spectroscopy as a rapid and non-destructive method for monitoring quality and authenticity of fish and meat products: Impact of different preservation conditions. Lwt, 103, 279-292. http://dx.doi. org/10.1016/j.lwt.2019.01.021.

Hernández, J. A. (2009). Use of neural networks and neural network inverse in optimizing food processes. Perspectives in Agriculture, Veterinary Science, Nutrition and Natural Resources, 4(61), 1-11. http://dx.doi.org/10.1079/PAVSNNR20094061.

Karoui, R., \& Blecker, C. (2011). Fluorescence spectroscopy measurement for quality assessment of food systems-a review. Food and Bioprocess Technology, 4(3), 364-386. http://dx.doi.org/10.1007/ s11947-010-0370-0.

King, T., Cole, M., Farber, J. M., Eisenbrand, G., Zabaras, D., Fox, E. M., \& Hill, J. P. (2017). Food safety for food security: relationship between global megatrends and developments in food safety. Trends in Food Science \& Technology, 68, 160-175. http://dx.doi. org/10.1016/j.tifs.2017.08.014.

Kucha, C. T., Liu, L., \& Ngadi, M. O. (2018). Non-destructive spectroscopic techniques and multivariate analysis for assessment of fat quality in pork and pork products: a review. Sensors, 18(2), 377. http://dx.doi. org/10.3390/s18020377. PMid:29382092.

Marine, J.-C. W., Dyer, M. A., \& Jochemsen, A. G. (2007). MDMX: From bench to bedside. Journal of Cell Science, 120(Pt3), 371-378. http://dx.doi.org/10.1242/jcs.03362. PMid:17251377.

McQueen, D. H., Wilson, R., Kinnunen, A., \& Jensen, E. P. (1995). Comparison of two infrared spectroscopic methods for cheese analysis. Talanta, 42(12), 2007-2015. http://dx.doi.org/10.1016/00399140(95)01685-6. PMid:18966444.

Meira, M., Quintella, C. M., Costa, P. R. No., Pepe, I. M., Ribeiro, E. M. O., Silva, W. L., Cid, A. L., \& Guimarães, A. K. (2015). Validation of LED spectrofluorimeter for determination of both biodiesel and nontransesterified residual cooking oil in diesel samples. Spectrochimica Acta. Part A: Molecular and Biomolecular Spectroscopy, 136(Pt B), 726-730. http://dx.doi.org/10.1016/j.saa.2014.09.088. PMid:25315867.

Meira, M., Quintella, C. M., Ribeiro, E. M. O., Guimarães, A. K., \& Silva, W. L. (2014). Determination of adulterants in diesel by multivariate calibration associated with LED spectrofluorimetry. International Journal of Chemistry, 6(4), 24. http://dx.doi.org/10.5539/ijc.v6n4p24.

Molajou, A., Nourani, V., Afshar, A., Khosravi, M., \& Brysiewicz, A. (2021). Optimal design and feature selection by genetic algorithm for Emotional Artificial Neural Network (EANN) in rainfall-runoff modeling. Water Resources Management, 35(8), 2369-2384. http:// dx.doi.org/10.1007/s11269-021-02818-2.

Nawrocka, A., \& Lamorska, J. (2013). Determination of food quality by using spectroscopic methods. In S. Grundas, \& A. Stępniewski (Eds.), Advances in agrophysical research. New York: Magnum Publishing. http://dx.doi.org/10.5772/52722.

Nikolova, K., Eftimov, T., Perifanova, M., \& Brabant, D. (2012). Quick fluorescence method for the distinguishing of vegetable oils. J Food Sci Eng, 2, 674-684

Nishi, K., Isobe, S.-I., Zhu, Y., \& Kiyama, R. (2015). Fluorescencebased bioassays for the detection and evaluation of food materials. 
Sensors, 15(10), 25831-25867.http://dx.doi.org/10.3390/s151025831. PMid:26473869.

Nourani, V., Molajou, A., Najafi, H., \& Mehr, A. D. (2019b). Emotional ANN (EANN): a new generation of neural networks for hydrological modeling in IoT. In F. Al-Turjman (Ed.), Artificial intelligence in IoT (pp. 45-61). Cham: Springer. http://dx.doi.org/10.1007/9783-030-04110-6_3.

Nourani, V., Molajou, A., Uzelaltinbulat, S., \& Sadikoglu, F. (2019a). Emotional artificial neural networks (EANNs) for multi-step ahead prediction of monthly precipitation; case study: northern Cyprus. Theoretical and Applied Climatology, 138, 1419-1434. http://dx.doi. org/10.1007/s00704-019-02904-x.

Nourani, V., Tajbakhsh, A. D., \& Molajou, A. (2019c). Data mining based on wavelet and decision tree for rainfall-runoff simulation. Hydrology Research, 50(1), 75-84. http://dx.doi.org/10.2166/nh.2018.049.

Olaimat, A. N., Shahbaz, H. M., Fatima, N., Munir, S., \& Holley, R. A. (2020). Food safety during and after the era of COVID-19 pandemic. Frontiers in Microbiology, 11, 1854. http://dx.doi.org/10.3389/ fmicb.2020.01854. PMid:32849446.

Petersen, M., Yu, Z., \& Lu, X. (2021). Application of raman spectroscopic methods in food safety: a review. Biosensors, 11(6), 187. http://dx.doi. org/10.3390/bios11060187. PMid:34201167.

Pignataro, M. F., Herrera, M. G., \& Dodero, V. I. (2020). Evaluation of peptide/protein self-assembly and aggregation by spectroscopic methods. Molecules, 25(20), 4854. http://dx.doi.org/10.3390/ molecules25204854. PMid:33096797.

Pouladzadeh, P., Kuhad, P., Peddi, S. V. B., Yassine, A., \& Shirmohammadi, S. (2016). Food calorie measurement using deep learning neural network. In Institute of Electrical and Electronics Engineers (Ed.), 2016 IEEE International Instrumentation and Measurement Technology Conference Proceedings (pp. 1-6). Taipei: IEEE. http:// dx.doi.org/10.1109/I2MTC.2016.7520547.

Ren, L., Meng, M., Wang, P., Xu, Z., Eremin, S. A., Zhao, J., Yin, Y., \& Xi, R. (2014). Determination of sodium benzoate in food products by fluorescence polarization immunoassay. Talanta, 121, 136-143. http://dx.doi.org/10.1016/j.talanta.2013.12.035. PMid:24607120.

Sádecká, J., \& Tóthová, J. (2007). Fluorescence spectroscopy and chemometrics in the food classification- a review. Czech Journal of Food Sciences, 25(4), 159-173.

Sahar, A., Rahman, U., Kondjoyan, A., Portanguen, S., \& Dufour, E. (2016). Monitoring of thermal changes in meat by synchronous fluorescence spectroscopy. Journal of Food Engineering, 168, 160165. http://dx.doi.org/10.1016/j.jfoodeng.2015.07.038.

Sharghi, E., Nourani, V., Molajou, A., \& Najafi, H. (2019). Conjunction of emotional ANN (EANN) and wavelet transform for rainfall-runoff modeling. Journal of Hydroinformatics, 21(1), 136-152. http://dx.doi. org/10.2166/hydro.2018.054.

Sharghi, E., Nourani, V., Najafi, H., \& Molajou, A. (2018). Emotional ANN (EANN) and wavelet-ANN (WANN) approaches for Markovian and seasonal based modeling of rainfall-runoff process. Water Resources Management, 32(10), 3441-3456. http://dx.doi.org/10.1007/ s11269-018-2000-y.
Shi, S., Zhang, Y., Xiong, X., Huang, K., Chen, X., \& Peng, M. (2012). The influence of flavonoids on the binding of pantoprazole to bovine serum albumin by spectroscopic methods: with the viewpoint of food/drug interference. Food Chemistry, 135(3), 1083-1090. http:// dx.doi.org/10.1016/j.foodchem.2012.05.049. PMid:22953828.

Sikorska, E., Górecki, T., Khmelinskii, I. V., Sikorski, M., \& Kozioł, J. (2005). Classification of edible oils using synchronous scanning fluorescence spectroscopy. Food Chemistry, 89(2), 217-225. http:// dx.doi.org/10.1016/j.foodchem.2004.02.028.

Sikorska, E., Wójcicki, K., Kozak, W., Gliszczyńska-Świgło, A., Khmelinskii, I., Górecki, T., Caponio, F., Paradiso, V. M., Summo, C., \& Pasqualone, A. (2019). Front-face fluorescence spectroscopy and chemometrics for quality control of cold-pressed rapeseed oil during storage. Foods, 8(12), 665. http://dx.doi.org/10.3390/ foods8120665. PMid:31835617.

Silva, C. E. T., Filardi, V. L., Pepe, I. M., Chaves, M. A., \& Santos, C. M. S. (2015). Classification of food vegetable oils by fluorimetry and artificial neural networks. Food Control, 47, 86-91. http://dx.doi. org/10.1016/j.foodcont.2014.06.030.

Szmatoła, M., Chrobak, J., Grabowski, R., Iłowska, J., Woch, J., Szwach, I., Semeniuk, I., Drabik, J., Wrona, M., Kozdrach, R., Orlińska, B., \& Grymel, M. (2018). Spectroscopic methods in the evaluation of modified vegetable base oils from Crambe abyssinica. Molecules, 23(12), 3243. http://dx.doi.org/10.3390/molecules23123243. PMid:30544618.

Tomazzoni, G., Meira, M., Quintella, C. M., Zagonel, G. F., Costa, B. J., Oliveira, P. R., Pepe, I. M., \& Costa, P. R. No. (2014). Identification of vegetable oil or biodiesel added to diesel using fluorescence spectroscopy and principal component analysis. Journal of the American Oil Chemists' Society, 91(2), 215-227. http://dx.doi. org/10.1007/s11746-013-2354-5.

Vasilescu, J., Marmureanu, L., \& Carstea, E. (2011). Analysis of seawater pollution using neural networks and channels relationship algorithms. Romanian Journal of Physics, 56(3-4), 530-539.

Wang, X., Guo, X.-Y., Xu, L., Liu, B., Zhou, L.-L., Wang, X.-F., Wang, D., \& Sun, T. (2017). Studies on the competitive binding of cleviprex and flavonoids to plasma protein by multi-spectroscopic methods: a prediction of food-drug interaction. Journal of Photochemistry and Photobiology. B, Biology, 175, 192-199. http://dx.doi.org/10.1016/j. jphotobiol.2017.08.037. PMid:28892755.

Xu, Y., Zhong, P., Jiang, A., Shen, X., Li, X., Xu, Z., Shen, Y., Sun, Y., \& Lei, H. (2020). Raman spectroscopy coupled with chemometrics for food authentication: a review. Trends in Analytical Chemistry, 131, 116017. http://dx.doi.org/10.1016/j.trac.2020.116017.

Yıldız, E., Saçmacı, Ş., Saçmacı, M., \& Ülgen, A. (2017). Synthesis, characterization and application of a new fluorescence reagent for the determination of aluminum in food samples. Food Chemistry, 237, 942-947. http://dx.doi.org/10.1016/j.foodchem.2017.06.055. PMid:28764090.

Zhou, L., Zhang, C., Liu, F., Qiu, Z., \& He, Y. (2019). Application of deep learning in food: a review. Comprehensive Reviews in Food Science and Food Safety, 18(6), 1793-1811. http://dx.doi.org/10.1111/15414337.12492. PMid:33336958. 